\title{
Ultrasonic evaluation regarding the effects of biological corrosion of historical roof trusses
}

\author{
Wojciech Skowroński ${ }^{1, *}$, and Bohdan Stawiski ${ }^{1}$ \\ ${ }^{1}$ Institute of Building Engineering, Faculty of Environment Development Engineering and Geodesy, \\ Wroclaw University of Environmental and Life Sciences, pl. Grunwaldzki 24, \\ 50-363 Wroclaw, Poland
}

\begin{abstract}
For many years work has been performed to obtain sufficiently accurate correlation between the results of ultrasonic tests and the results of strength tests for evaluation of the strength parameters of wood in a structure. It is also important to ensure the development of methods which will facilitate the work of construction mycologists; that is, non-invasive methods of determining the volume of missing materials caused by biological corrosion. The study presents the idea of the objective examination of the thickness of a corroded layer by measuring the velocity of ultrasonic pulse along the fibre length using for this spot heads with thin waveguides. Another testing method presented in the study is controlling the velocity of ultrasonic wave in the direction tangential to annual growth rings by conducting tests on the corner of the corroded beam.
\end{abstract}

\section{Introduction}

Use of the ultrasonic method to evaluate the technical condition of fresh wood, especially when not built-in, is easy. Problems appear when structures, that is built-in wood, need to be examined. The ends of the element are usually inaccessible, therefore it is impossible to check the wood along the fibres. However, the side surfaces are accessible, so there are not any counterindications to examining the structure in the direction tangent to its annual growth rings. This is important because wood, as an anisotropic material, has different properties in three dimensions. For conifer wood dried up to $8 \%$, if tensile strength of $100 \%$ is assumed, then bending strength is approx. $72 \%$, strength for compression along the fibres approx. $44 \%$ and for shearing along the fibres $6.3 \%$.

With respect to its composition, wood is a heterogenous material having numerous defects connected with its biological origin, and wood properties are tested at the level of macroscopic, microscopic and sub-microscopic composition. The results of these tests are material parameters which are commonly used in analyses of structures. If it is assumed that wood can be regarded as a homogenous matter and the elastic susceptibility tensor is described by $S_{\mathrm{rs}}$ indices $(r, s=1,2,3,4,5,6)$, then based on the Hook's law the following equation is formulated:

\footnotetext{
* Corresponding author: wojciech.skowronski@upwr.edu.pl
} 


$$
\left\{\begin{array}{l}
\varepsilon_{x} \\
\varepsilon_{y} \\
\varepsilon_{z} \\
\gamma_{y z} \\
\gamma_{z x} \\
\gamma_{x y}
\end{array}\right\}=\left[\begin{array}{llllll}
S_{11} & S_{12} & S_{13} & & & \\
S_{21} & S_{22} & S_{23} & & & \\
S_{31} & S_{32} & S_{33} & & & \\
& & & S_{44} & & \\
& & & & S_{55} & \\
& & & & & S_{66}
\end{array}\right]\left\{\begin{array}{l}
\sigma_{x} \\
\sigma_{y} \\
\sigma_{z} \\
\tau_{y z} \\
\tau_{z x} \\
\tau_{x y}
\end{array}\right\}
$$

This statement is obtained taking into account the identicality of coordinate indications

$$
x \equiv x_{1}, y \equiv x_{2}, z \equiv x_{3}
$$

Assuming that wood is a material considered in the coordinate system in which the $\mathrm{L}, \mathrm{T}$ and $\mathrm{R}$ axes are oriented along fibres, tangentially and radially, respectively, the analysis may include characteristic values of modules such as: $E_{\mathrm{T}}-$ modulus of elasticity in the tangential direction, across the fibres, $E_{\mathrm{L}}$ - modulus of elasticity along the fibres, $E_{\mathrm{R}}$-modulus of elasticity in the radial direction, $G_{\mathrm{LR}}$ - modulus of transverse elasticity on the radial surface (shear module), $G_{\mathrm{RT}}$ - module of transverse elasticity on the front surface and $G_{\mathrm{LT}}$ - modulus of transverse elasticity on the tangential surface and six Poisson's rations: $v_{\mathrm{LT}}, v_{\mathrm{TL}}, v_{\mathrm{TR}}, v_{\mathrm{RT}}, v_{\mathrm{LR}}, v_{\mathrm{RL}}$. For example $S_{11}=1 / E_{T}, S_{66}=1 / G_{L T}, S_{12}=-v_{T L} / E_{T}$. However, strength is the most frequently examined parameter. Strength is significantly affected by wood moisture; another factor having an effect is temperature, and then wood density. Dependencies describing this effect are well known, they are presented in standards and technical literature e.g. [1,2].

A much more complicated task is the testing of strength parameters in existing structures, especially in old historical wooden structures, sometimes several hundred years old.

\section{Example of a historical, several hundred years old wooden roof truss}

The described object is a building located in the centre of Wrocław - a compact complex of gothic prison structures (pearl of the Middle Ages). This is one of the oldest public utility buildings surviving until now (it reaches the first half of the 14 century); it obtained its current shape in the second half of the $17^{\text {th }}$ century. According to a legend, Wit Stwosz served a sentence in this building for forging a bill of exchange.

After the Second World War, the well-preserved building was secured. In addition, major renovation was performed in the years 1967-1973. Tie rod anchors are visible on the building elevation (Fig. 1) and generally the interior of the building complex is an attractive courtyard shown in Fig. 2. 


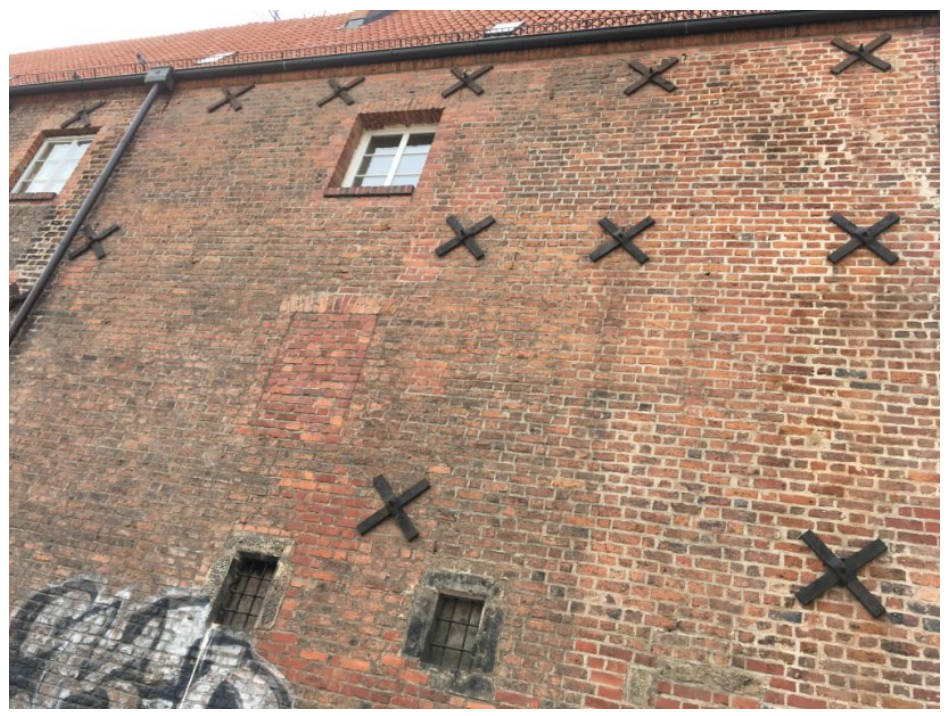

Fig. 1. Anchors of tie rods fastening the building in the complex of diagnosed object.

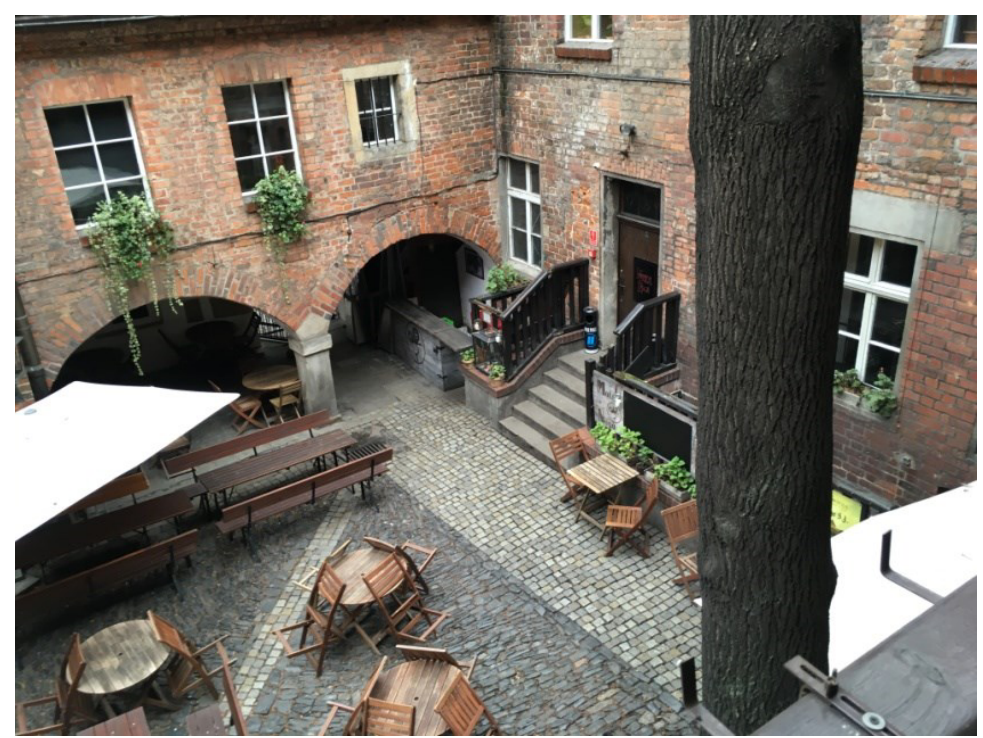

Fig. 2. Courtyard surrounded by the complex of the described buildings.

The tests were conducted, among other things, on the roof truss of the building with pillars shown in Fig. 3.

Traces indicating the existence of insects were found in structural elements of the roof truss in the examined building (Fig. 4 and 5). However, there are still relatively few places where biological corrosion occurred. Old traces of 'corridors' after technical wood pests are visible in the elements. They are, for instance, old traces after larval tunnels. Single traces of beetle activity by were also noticed. In addition, relatively fresh traces of a wood pest feeding area filled with wood flour were discovered which can be seen in Fig. 6. 


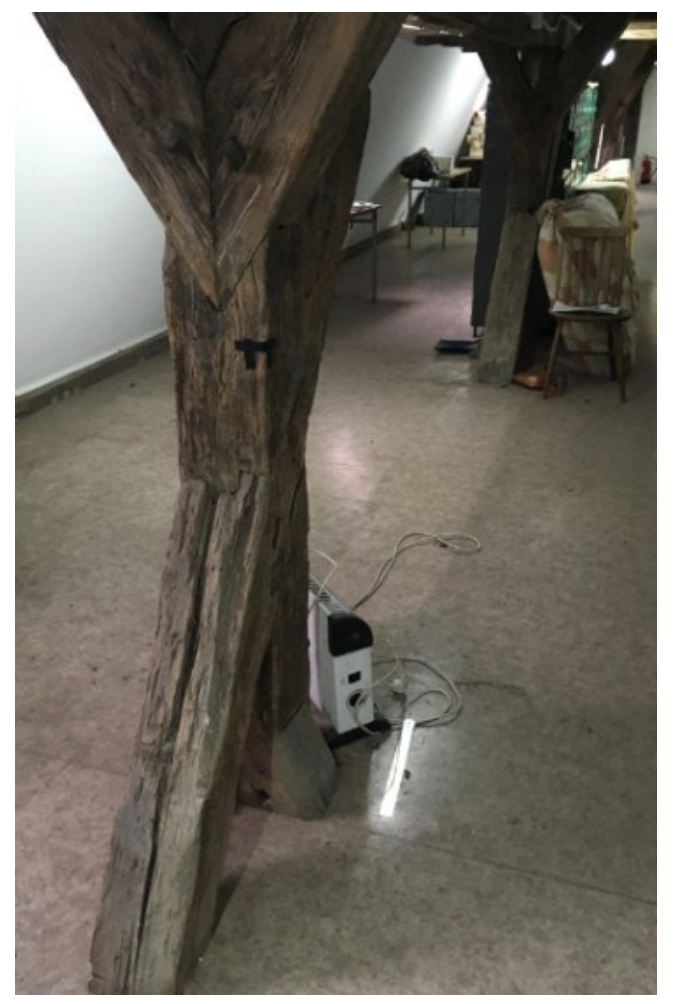

Fig. 3. Roof truss pillar with heavily corroded lower brace.

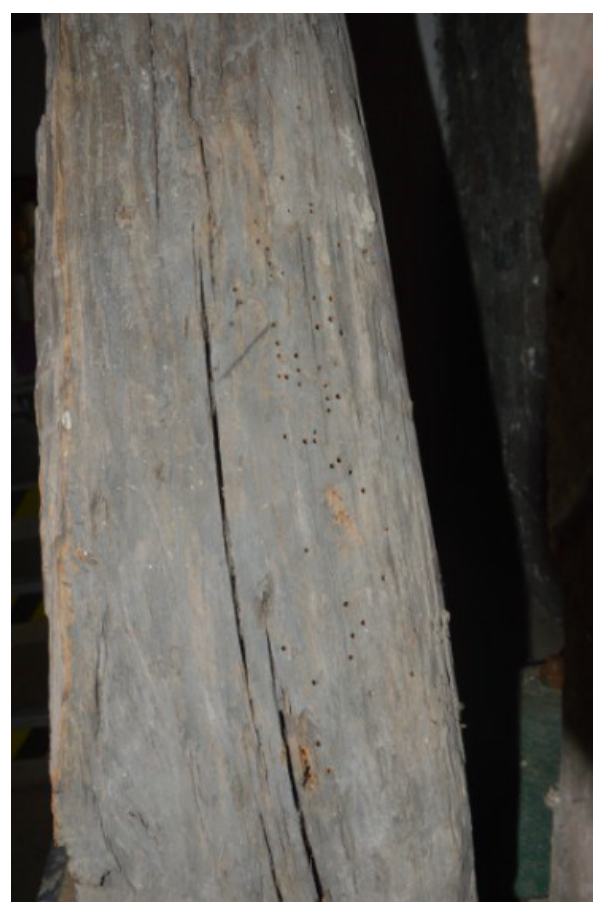

Fig. 4. Beetle exit holes. 


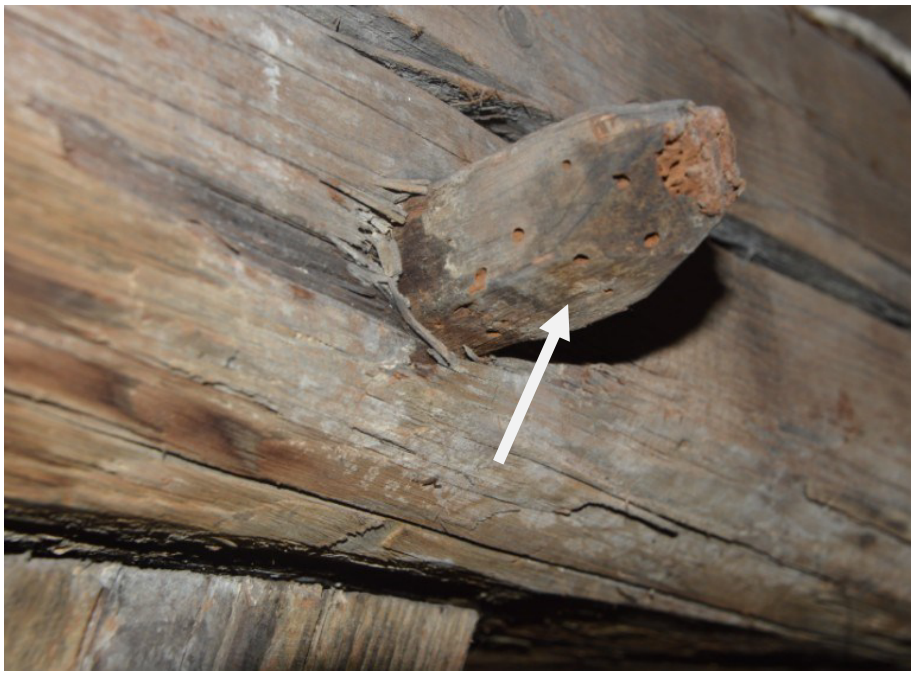

Fig. 5. Beetle exist holes.

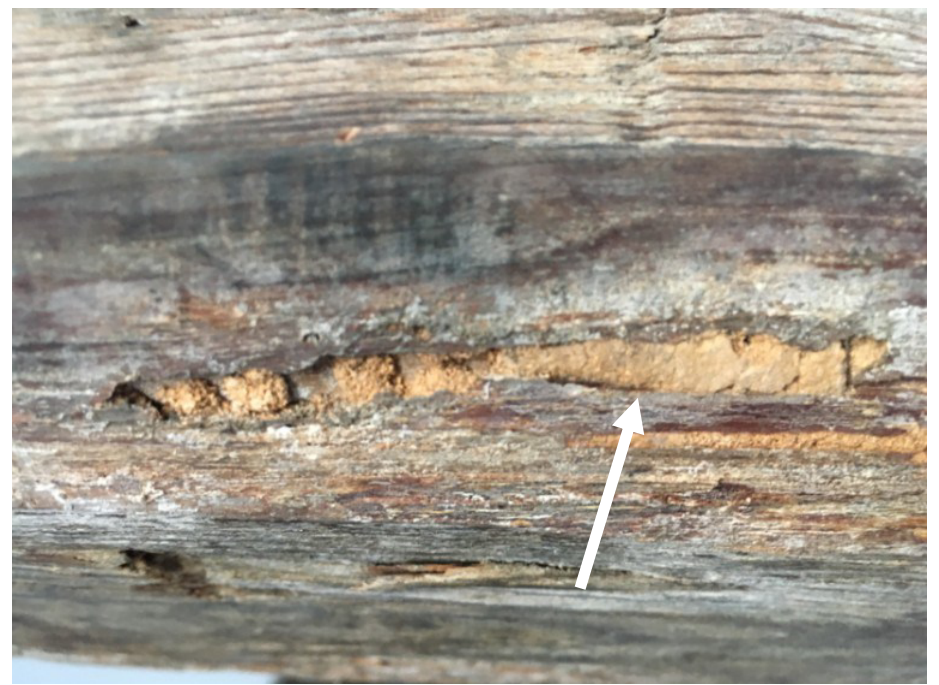

Fig. 6. Fresh traces of wood pest feeding area filled with wood flour.

\section{Ultrasonic tests of old structures made of wood}

There are a number of difficulties in methodology of testing old wooden structures using ultrasound. One of them is the uneven surface of the beams because of old methods of wood processing (e.g. beams obtained by means of hewing) or because of mechanical defects which appeared during use (Fig. 7).

Another difficulty results from cracks the depth of which may vary, as they extend the time of transfer from the transmitting to the receiving head or completely block transfer of ultrasounds (Fig. 8).

In order to control the flow of ultrasounds in the examined structural element more accurately, heads with long thin waveguides were used thanks to which it was possible to test flow of ultrasounds both along the fibres (Fig. 9) and tangentially to the rings (Fig. 10). 
Tests along the fibres are useful if, for example, we want to determine the depth of the zone destroyed by insects. The test consists in drilling two holes $\varnothing 2-3 \mathrm{~mm}$ at a specified distance $l$ from each other $(5-7 \mathrm{~cm})$ and measuring the time of transfer for wave $t$ or speed of pulse $c$.

$$
c=l, t
$$

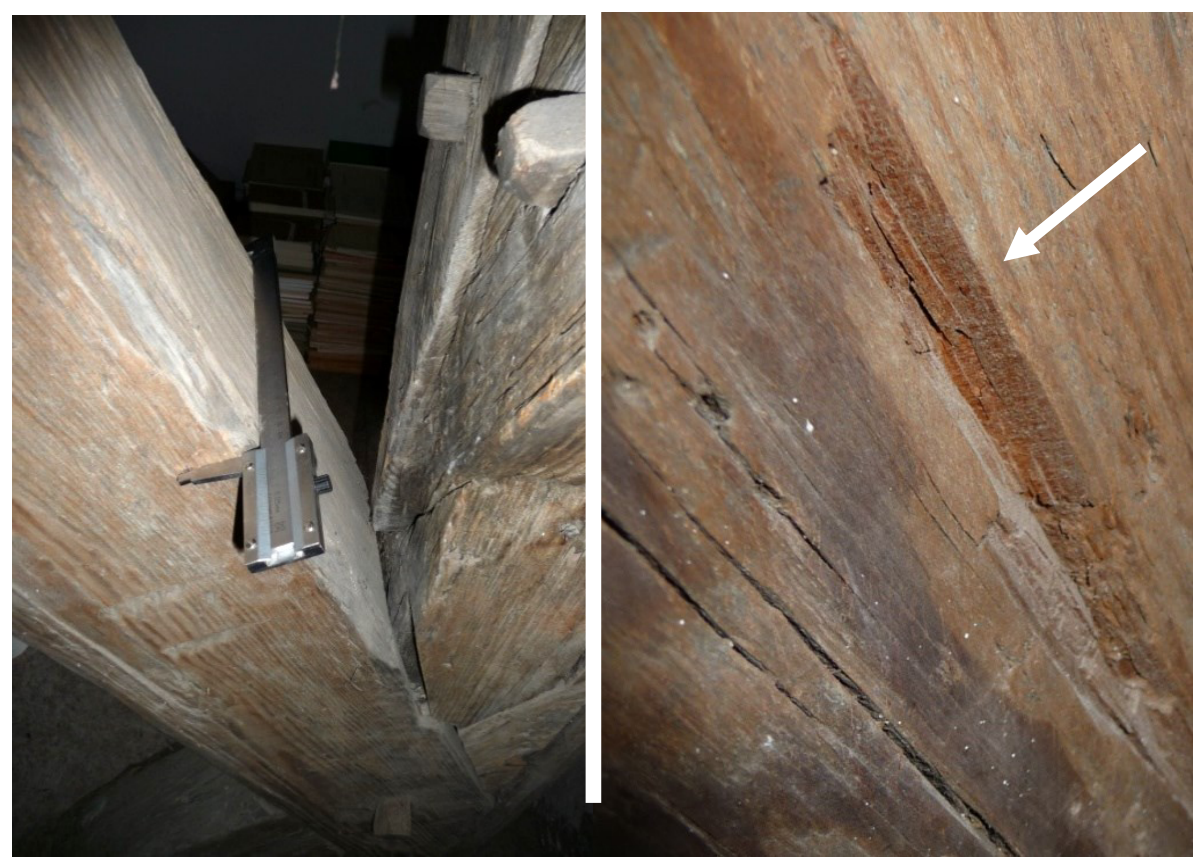

Fig. 7. Natural unevenness caused by the old technique of cutting beams and mechanical defects.

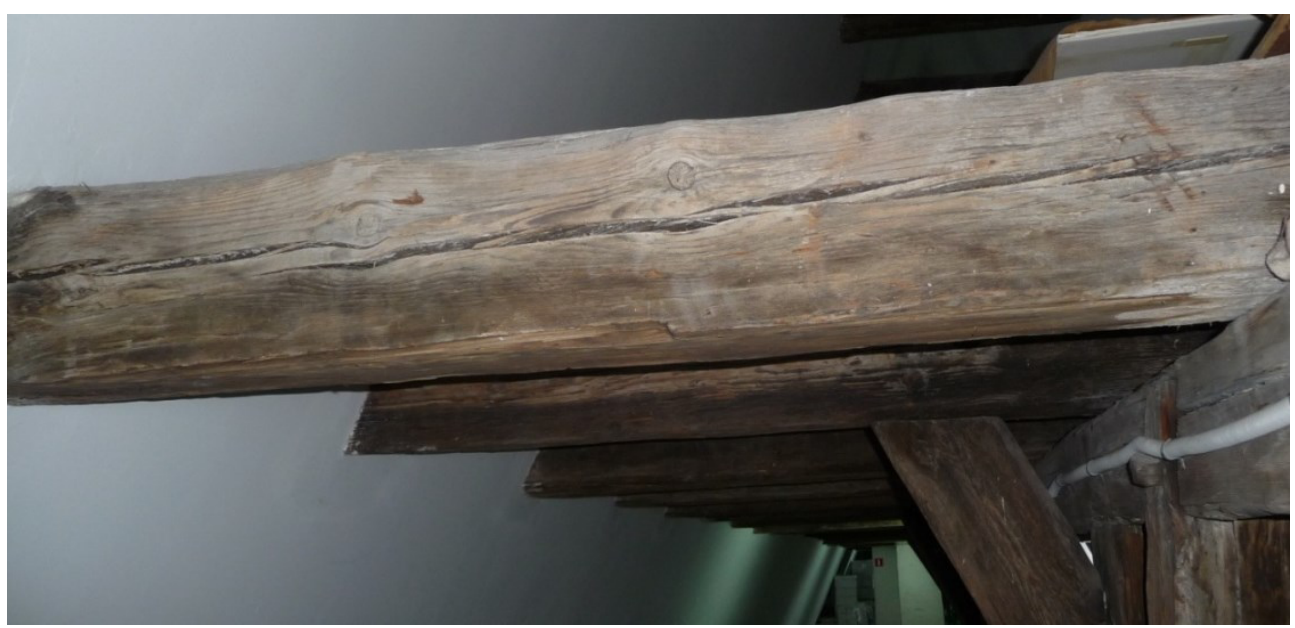

Fig. 8. Cracks in wooden beams of various depths and in various places of cross-section.

Ultrasound speed in corroded wood with larval galleries is very low. The thickness of the corroded zone will be determined, if after subsequent deepening the speed increases up to the expected level. 

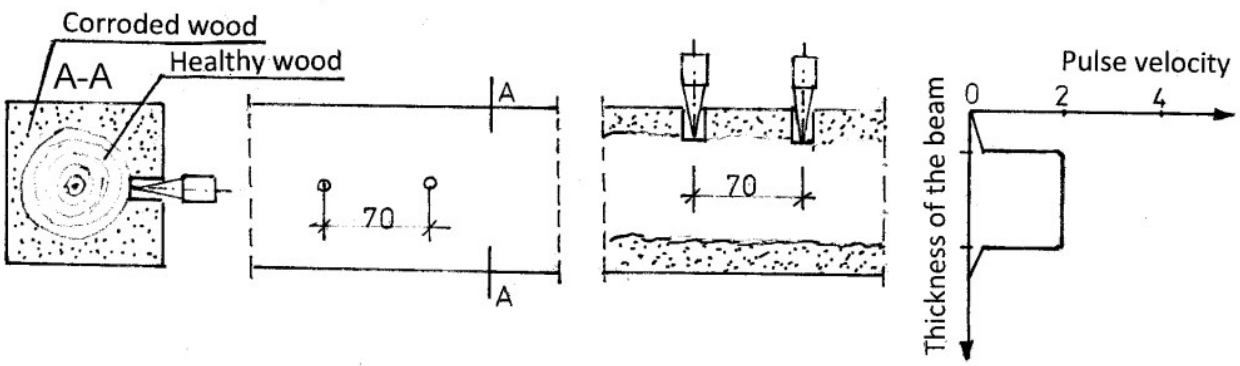

Fig. 9. Method of testing a wooden element using ultrasounds along the fibres.

Another method of testing wood in the tangential direction is simpler and does not cause any damage (drilling). Any corner of the cross-section (Fig. 11) should be selected for testing. Mark $3-4$ points on each of the adjacent sides of the beam. Measure the distance to them from the corner, calculate the distances of wave flow, verify them by measuring the diagonal using a calliper (the angle is not always right). The testing method is illustrated in Fig. 12.

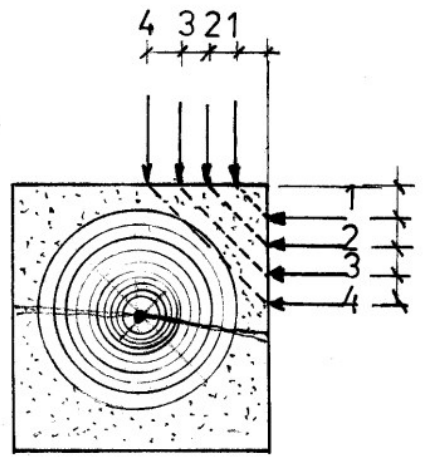

a)

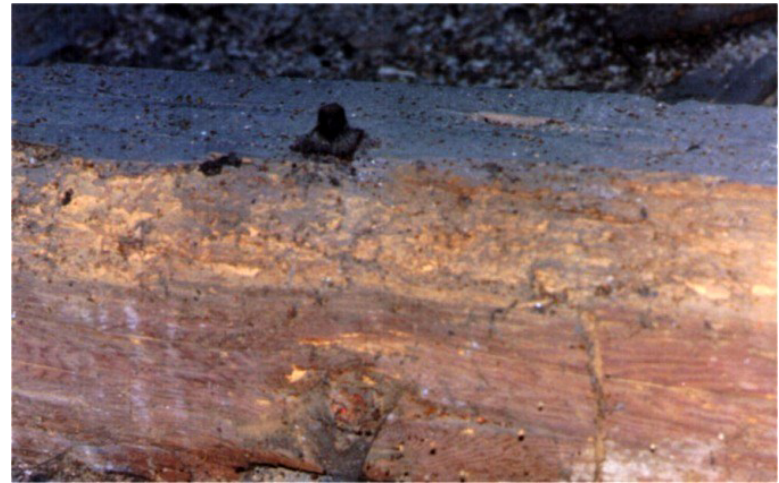

b)

Fig. 10. a) Method of measuring the wooden element damaged by insects using ultrasounds; b) example of beam heavily damaged by insects.

Elements of the examined roof truss had few exit holes from past insect activity. Conventional methods of tapping and puncturing wood did not allow satisfactory assessment of the degree of damage. Therefore, the ultrasonic method with exponential heads, frequency $40 \mathrm{kHz}$, was used. The heads ran with ultrasonic probe Unipan 543 [3]. Time of pulse transfer via waveguide $t_{0}=34.2 \mu \mathrm{s}$. Two areas were selected to check whether a few inset exit holes may indicate essential damage of elements or whether they can be regarded as insignificant as far as weakening of the cross-section is concerned.

The first examined area was a corner of the big brace (Fig. 11 and 12), not having any mechanical damage apart from traces of insect feeding (corner 1), the second was a corner of the pillar which had quite considerable losses of wood indicating scratches along the fibres (corner 2). Results from tests of both corners are shown in Table 1. 


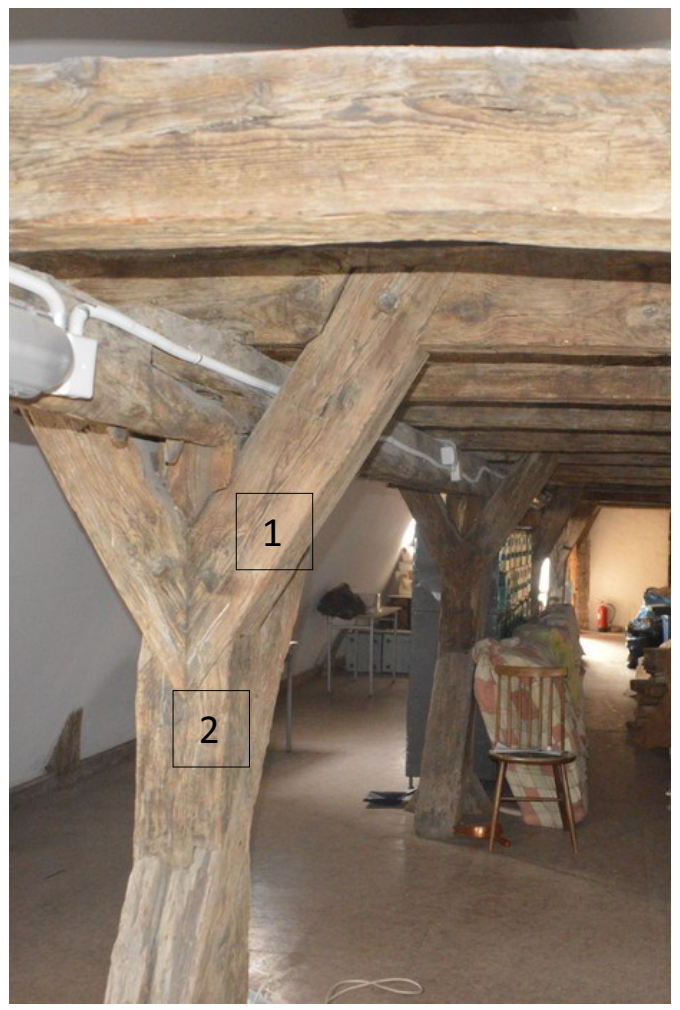

Fig.11. Historical roof truss

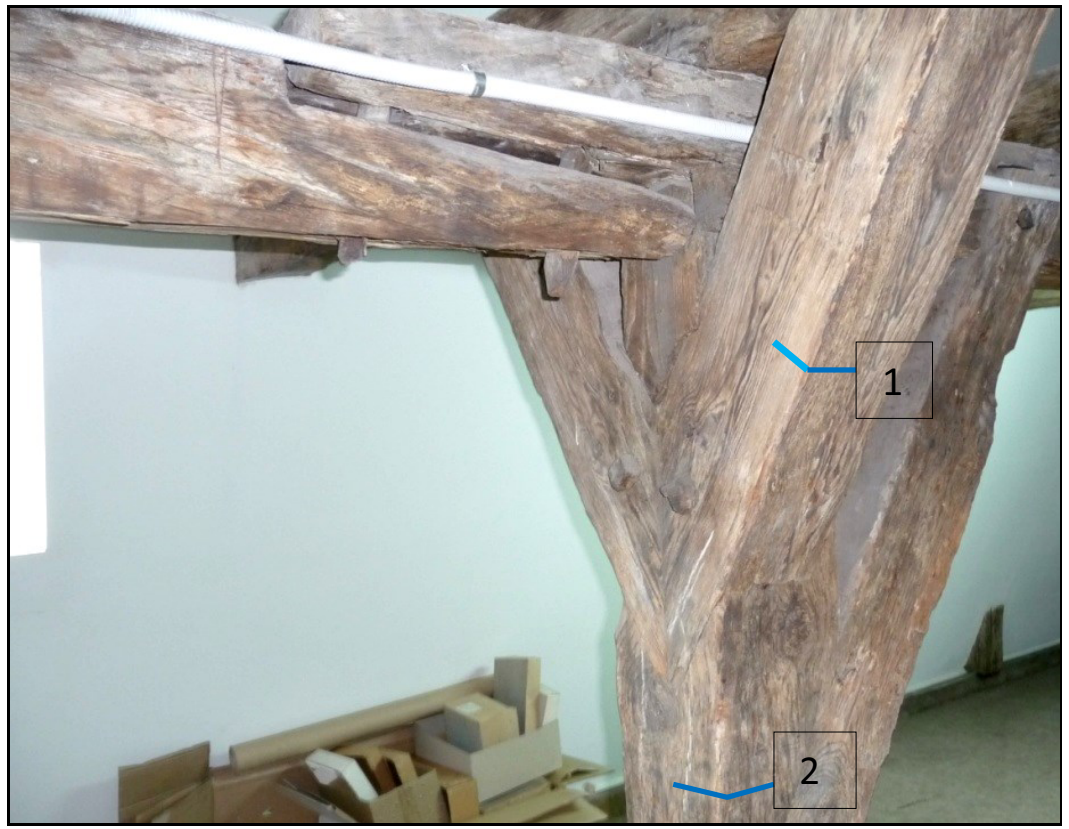

Fig.12. Fragment of historical roof truss tested using ultrasounds; brace and pillar - area (corner) 1 and 2. 
Corner 1 was made of wood without visible damage apart from two exit holes nearby, corner 2 also had mechanical defects and more exit holes nearby.

Table 1. Ultrasound pulse speed on the tested distances of both corners

\begin{tabular}{|c|c|c|c|c|c|}
\hline $\begin{array}{c}\text { Area } \\
\text { (Corner) }\end{array}$ & $\begin{array}{c}\text { Section } \\
(\text { see Fig.3) }\end{array}$ & $\begin{array}{c}\text { Distance } \\
l[\mathrm{~mm}]\end{array}$ & $\begin{array}{c}\text { Gross time } \\
t_{\text {br }}[\mu \mathrm{s}]\end{array}$ & $\begin{array}{c}\text { Net time } \\
t_{\mathrm{n}}[\mathrm{mm}]\end{array}$ & $\begin{array}{c}\text { Speed } \\
c[\mathrm{~km} / \mathrm{s}]\end{array}$ \\
\hline 1 & C-D & 23.4 & 53.1 & 18.9 & 1.238 \\
& B-E & 47.6 & 71.0 & 36.8 & 1.293 \\
& A-F & 73.5 & 91.2 & 57.0 & 1.289 \\
\hline 2 & C-D & 27.3 & 59.2 & 25.0 & 1.12 \\
& B-E & 51.8 & 79.6 & 45.4 & 1.15 \\
& A-F & 75.0 & 102.2 & 68.0 & 1.11 \\
\hline
\end{tabular}

The scheme of the testing method and ultrasonic test method is shown in Fig. 13. Identification of measurement sections and the method of testing the wooden element using the ultrasonic method with 'spot' heads can be seen on it.

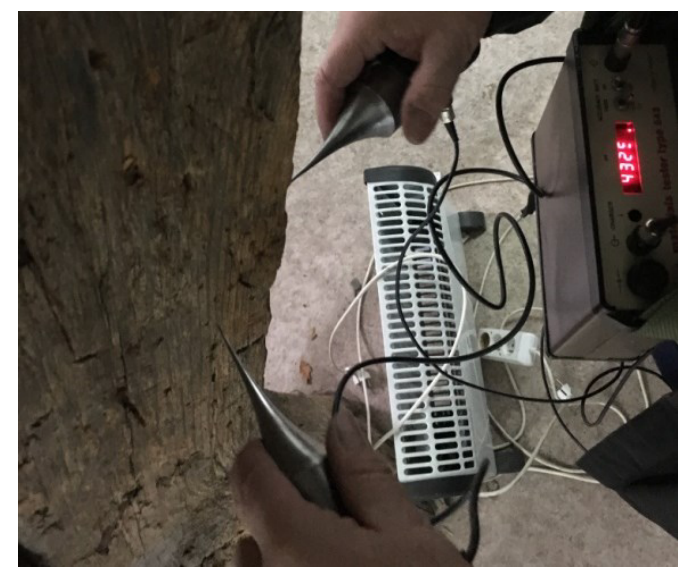

Fig. 13. Structure during tests.

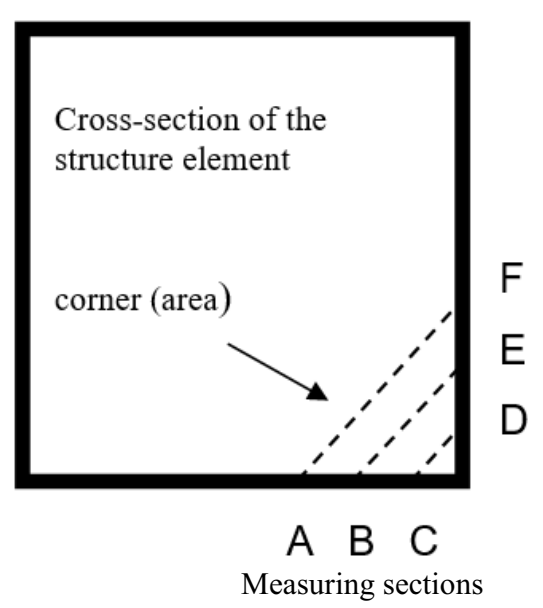

(see Table 1)

\section{Comments and conclusions}

It can be concluded from the completed tests that in area 1 the speed on all distances was at the level close to $1.29 \mathrm{~km} / \mathrm{s}$. Only near the corner itself was it slightly lower at $1.25 \mathrm{~km} / \mathrm{s}$. No noticeable reduction of strength due to damage caused by insect larvae appeared in this area. In area no. 2, although the average speed is slightly lower at $1.1 \mathrm{~km} / \mathrm{s}$, it does not change on increasing the distance. Such a small change of speed may be connected with different wood from which the examined beam had been cut out. The reference point was health wood in which no damage was found.

The ultrasonic defectoscopy is one of the essential non-destructive methods of testing materials. In this case, propagation of a high frequency acoustic wave in the given object was analysed which allows detection, for example, of heterogeneity and defects of the matter. This method consists in emitting ultrasounds and registering them after passage through the substance under test.

There are a number of difficulties in the methodology of testing old wooden structures using ultrasounds. At the same time, hope is expressed that in the future it will be possible to obtain sufficiently good, for diagnostic purposes (for evaluation of wooden structures of 
buildings), correlation of results from ultrasonic tests with results of strength tests in order to evaluate strength parameters for wood in the structure.

Obviously, other methods of non-destructive tests (NDT) are also examined which allow more and more accurate identification of the mechanical and physical properties of materials (including wood) and elements of the structure [4-10]. It is also important to develop methods which will facilitate the work of construction mycologists aimed at discovering defects and missing parts of materials caused by biological corrosion. This concerns the work which can be performed without infringing the continuity and structure of the building.

\section{References}

1. A. Cavalli, D. Cibecchini, M. Togni, H. S. Sousab, J. Constr. Build. Mater., 114, pp. 681-687 (2016)

2. J. Bláha, M. Kloiber, Stav. Mat., 10, pp. 38-40 (2008)

3. T. Gudra, B. Stawiski, NDT\&E International, 33, pp. 1-6 (2000)

4. P.B. Lourenço, A.O. Feio, J.S. Machado, Constr. Build. Mater., 21, pp. 1617-1627 (2007)

5. M. Piazza, M. Riggio, J. Build. Apprais., 3, pp. 267-296 (2008)

6. J. Branco, M. Piazza, P. Cruz, Constr. Build. Mater., 24, pp. 371-383 (2010)

7. J.-L. Sandoz, Wood Sci. Technol., 23, pp. 95-108 (1989)

8. F.E. Finney, R.C. Chivers, J.A. Evertsen, J. Keating, Ultrasonics, 36, pp. 449-453 (1998)

9. B. Kasal, R. Anthony, Prog. Struct. Eng. Mat., 6, pp. 94-103 (2004)

10. T. Kruglowa, Y. Sandin, R.I, Kliger, Int. J. Archit. Herit., 7, pp. 416-433 (2013) 